\title{
Compatibilidad entre debido proceso y eficiencia: su aplicación al régimen de apelación en el proceso civil chileno
}

\author{
Raúl Núñez Ojeda* \\ Nicolás Carrasco Delgado** \\ Martín Coronado Atenas***
}

\begin{abstract}
RESUMEN
En este trabajo trataremos de demostrar a partir de una institución procesal civil (inadmisibilidad del recurso de apelación), la posibilidad de compatibilizar las exigencias de debido proceso con consideraciones de eficiencia. En efecto, el aporte del Análisis Económico del Derecho permite entregar pautas de regulación que mejoran la institución mencionada.
\end{abstract}

Apelación - análisis económico del derecho procesal - debido proceso - inadmisibilidad

\section{Compatibility between due process of law and efficiency: application to the chilenan civil appeal procedure}

\begin{abstract}
In this work will try to demonstrate by a civil procedure institution (appeals inadmissibility), the chance to juggle due process of law requirements with efficiency considerations. In fact, Economic Analysis of Law grounds provides regulation policies that enhance the mentioned institution.
\end{abstract}

Appeal - economic analysis of law - due process of law - inadmissibility

* Licenciado en Ciencias Jurídicas, Universidad de Valparaíso. Doctor en Derecho, Universidad Pompeu Fabra de Barcelona. Profesor de Derecho Procesal Civil y Penal en la Pontificia Universidad Católica de Valparaíso. Correo electrónico: raul.nunez@pucv.cl

** Licenciado en Ciencias Jurídicas, Universidad de Chile. Magíster en Derecho, Universidad de Chile. Profesor Asistente de Derecho Procesal Facultad de Derecho Universidad de Chile. Correo electrónico: ncarrascod@gmail.com

*** Licenciado en Ciencias Jurídicas, Universidad de Chile. Diplomado en Derecho Público Económico, Universidad de Chile. Ayudante del Departamento de Derecho Procesal de la Facultad de Derecho de la Universidad de Chile. Correo electrónico: m_coatenas@hotmail.com

Este trabajo se enmarca dentro del proyecto FONDECYT regular No 1150468 , que lleva por título: "Dirección material y gestión eficiente de los procesos civiles", cuyo investigador principal es el profesor Dr. Álvaro Pérez Ragone.

Artículo recibido el 27 de abril de 2017 y aceptado para su publicación en este número el 23 de julio de 2018 


\section{EXORDIO}

$\mathrm{E}$

n este trabajo abordaremos una institución regulada en el proceso civil chileno: el régimen del recurso de apelación.

Tal institución es un buen ejemplo para sostener que las consideraciones de eficiencia que provienen del Análisis Económico del Derecho (AED) son perfectamente compatibles con consideraciones de debido proceso. De hecho, estos criterios de eficiencia sirven para mejorar el estado de la cuestión normativa que ha sido desarrollado respecto de tal garantía fundamental.

Pretendemos dar a conocer una posición que permite compatibilizar, en el marco del Derecho Procesal, exigencias de eficiencia con debido proceso, más allá del rechazo inicial que pudiera existir de esa idea.

Tal objetivo resulta novedoso en la literatura del civil law, y más aún en el ámbito del Derecho Procesal. Por eso, también pretendemos generar discusión respecto de estos tópicos y, en su oportunidad, extender este análisis de compatibilidad a otras instituciones procesales.

Además de un capítulo inicial acerca de consideraciones generales de Análisis Económico del Derecho Procesal (AEDPR), este trabajo está estructurado en los siguientes capítulos: Capítulo 2 que trata el derecho al recurso en el proceso civil chileno; Capítulo 3 que consiste en el examen de compatibilización respecto del régimen de apelación en el proceso civil chileno, y Capítulo 4 que contiene las conclusiones.

\section{Aspectos generales del AED e introducción a la Adecuación DE EXIGENCIAS DE DEBIDO PROCESO Y EFICIENCIA}

\section{El AED Normativo y Positivo}

La pregunta ¿de qué manera se afecta el comportamiento humano con la promulgación de una norma jurídica determinada? va a producir una respuesta distinta a la pregunta ¿por qué resulta preferible un conjunto normativo que promueve la eficiencia, a otro que no?

En efecto, la respuesta a la primera pregunta supone que los sujetos actúan como entes que tienden a maximizar sus beneficios, de manera que considerarán la norma jurídica promulgada como un precio implícito en la toma de sus decisiones ${ }^{1}$. Lo anterior constituye el objeto del Análisis Económico del Derecho Positivo (AEDPS). Por su parte, la respuesta a la segunda pregunta busca generar un cambio normativo sobre la base de una premisa de eficiencia en la asignación de los recursos. Lo anterior constituye el objeto del Análisis Económico del Derecho Normativo (AEDN).

${ }^{1}$ Cooter, R. y Ulen, T., Derecho y Economía, Ciudad de México D.F., Fondo de Cultura Económica, 1998, p. 14. 
Considerando lo anterior, podemos definir ambas perspectivas de la siguiente forma, a saber: el AEDPS pone énfasis en la descripción y explicación del contenido de un conjunto normativo o de prácticas contractuales. Por su parte, el AEDN tiene como tarea determinar cómo el ordenamiento jurídico puede ser utilizado para obtener determinados fines, como la prevención de conductas indeseadas o ineficientes, desde la óptica de la economía ${ }^{2}$. En otras palabras, el análisis positivo describe la situación tal cual es, en cambio, el examen normativo prescribe cómo debe ser dicha situación.

\section{Análisis Económico del Derecho Procesal (AEDPR)}

De acuerdo con la literatura del AEDPR los objetivos que deben buscarse en dicha área jurídica involucran la reducción de dos clases de costos, a saber: la reducción de los costos del sistema judicial ("costos administrativos") y la reducción de los costos del error ${ }^{3}$ (“costos del error”). Desde dicha perspectiva, una solución eficiente sería aquella que ponderara ambas clases de costos, pues esa es la forma de obtener una respuesta óptima.

Por otro lado, las exigencias del debido proceso legal constituyen resguardos que no pueden ser soslayados ${ }^{4}$ y que, indudablemente, imponen trámites, diligencias, o etapas procesales de carácter formal que acrecientan la inversión en justicia. Por lo mismo, podríamos pensar que los objetivos del AEDPR resultan ajenos y opuestos a las exigencias que hemos señalado en el párrafo anterior. Sin embargo, ello no es así, por ejemplo, Richard Posner, quien implícitamente analiza este problema, consagra una fórmula matemática tendiente a determinar cuándo se niega el debido proceso a un ciudadano que exige acceso a la justicia, señalando en tal sentido que:

"En los términos de la fórmula de $\mathrm{Hand}^{5}$, se niega el proceso debido cuando $\mathrm{B}<$ PL donde $\mathrm{B}$ es el costo de la salvaguarda procesal, $\mathrm{P}$ es la probabilidad de error si se niega la salvaguarda, y L es la magnitud de la pérdida si se materializa el error"6.

2 Paolantonio, M. E., "El análisis económico del derecho y la estructura societaria”, en KLUGER, V. (coord.), Análisis Económico del Derecho, Editorial Heliasta, Buenos Aires, 2006, p. 207.

${ }^{3}$ Cooter, R. y Ulen, T., ob. cit., pp. 530-532; y Posner, R., El análisis económico del Derecho, Fondo de Cultura Económica, Ciudad de México, DF, Fondo de Cultura Económica, 1992, pp. 549-551.

${ }^{4}$ Cooter, R. y Ulen, T., ob. cit., p. 483. Para un mayor análisis de esta materia, ver: Nogueira, H., El debido proceso en la Constitución y el sistema interamericano, Librotecnia, Santiago, 2007, pp. 42-56.

${ }^{5}$ La famosa fórmula Hand fue creada por el juez federal norteamericano don Learned Hand, a raíz de su participación en el caso Estados Unidos contra Carroll Towing Co. (UnitedStates v. Carroll Towing Co., 159 F. 2d 169 (2d Cir. 1947). Es importante señala que la fórmula Hand, utilizada en materia de responsabilidad civil, pretende determinar cuándo una conducta es negligente, afirmando dicha imprudencia si la acción se lleva a cabo en supuestos en que el gasto de previsión $(\mathrm{Gp})$ es menor que el daño previsto (D) multiplicado por la probabilidad que ello ocurra (P). Dicha función se expresa como sigue: $\mathrm{Gp}<\mathrm{D}$ x P (SCHAFER, H.B. y Oтт, C., Manual de Análisis Económico del Derecho Civil, Tecnos, Madrid, 1991, pp. 109-111).

${ }^{6}$ Posner, R., ob. cit., p. 520. 
Aplicando dicha fórmula a la materia aquí tratada, se llega a la conclusión de que se respeta el debido proceso, en materia de acceso a la justicia, si es el caso que un Tribunal se niega a dar una audiencia a un sujeto (derecho a ser oído) en el evento que el costo del respeto de la garantía sea mayor que la probabilidad del error si se niega la salvaguarda, multiplicado por la entidad de la pérdida si se materializa el error. Si se produce el caso contrario, entonces, debe concederse al ciudadano el derecho a ser oído por el órgano jurisdiccional.

A partir del examen de la fórmula mencionada, que materializa las exigencias y propósitos del AED, podríamos concluir que en su formulación se posibilita una ponderación de los intereses involucrados en el resguardo del debido proceso, así como los criterios tendientes a la optimización de los costos sociales, por lo que la contradicción intuitiva antes indicada no sería tal. Evidentemente esta conclusión debe ser examinada a la luz de instituciones procesales, en particular donde estas exigencias concurran.

\section{El DERECHO AL RECURSO EN EL PROCESO CIVIL CHILENO}

Es ampliamente conocido que existe un derecho fundamental a una tutela jurisdiccional efectiva en el derecho internacional de los derechos humanos (en su vertiente procesal), lo que no ocurre en el derecho interno nacional por no existir normativa que así lo consagre. Es más, el Excmo. Tribunal Constitucional en su labor interpretativa de la Constitución se ha encargado de delimitar el concepto, como se verá más adelante. En este contexto, es posible derivar de ello la existencia de un derecho fundamental al recurso o la posibilidad de control por parte de un tribunal superior en todo caso e, incluso, ¿la noción constitucional de debido proceso incluye el derecho al recurso?

Para dar una respuesta hay que distinguir entre el proceso penal y el proceso civil. En el proceso penal no cabe duda que el derecho al recurso sí está consagrado en el debido proceso, "pero solo respecto del proceso penal y particularmente a favor del afectado por una sentencia condenatoria. En el sentido clásico de revisión, el Tribunal Constitucional español y la Corte Europea de Derechos Humanos (...) coinciden con esta idea, de que solo tiene derecho al recurso el condenado y no el Ministerio Público (o acusador fiscal)"7.

En lo que respecta al proceso civil, adherimos a la tesis de que en el ámbito del derecho procesal civil no existe un derecho al recurso como ocurre en el proceso penal ${ }^{8}$.

${ }^{7}$ Núñez, R. y Pérez Ragone, Á., Manual de Derecho Procesal Civil, Los medios de impugnación. Thomson Reuters, Santiago, 2015, p. 16. En el mismo sentido, los autores para justificar la posición restrictiva del recurso respecto del Ministerio Público, señalan que: "Ello tiene su fundamento en el principio de non bis in idem. Si el Estado fracasa en su pretensión punitiva y el imputado es absuelto, pierde la posibilidad de recurrir nuevamente ante los tribunales. Esta idea tiene su desarrollo también en el derecho angloamericano bajo la noción del double jeopardy, que constituye una versión extremada del non bis in ídem".

${ }^{8}$ Ver: YÁÑEZ, R., Derecho al recurso en el proceso penal, Tirant lo Blanch, Valencia, 2001, passim. y NúÑEZ, R., "El sistema de recursos procesales en el ámbito civil en un estado democrático deliberativo", en Revista Ius et Praxis, 2008 ( $\left.\mathrm{N}^{\circ} 14\right)$. 
Las voces que sostienen lo contrario -señalando que efectivamente existe un derecho al recurso en el proceso civil- formulan sus argumentos basándose en los tratados internacionales ratificados por Chile, particularmente la Convención Americana sobre Derechos Humanos (CADH) y el Pacto Internacional de Derechos Civiles y Políticos $(\mathrm{PIDCP})^{9}$.

Sin embargo, la revisión de los tratados internacionales en materia de derechos humanos "permite afirmar que el derecho a recurrir en juicios civiles no es un derecho reconocido por dichos tratados y, por esta razón, los Estados tienen libertad para establecer o no formas de impugnación considerando distintos criterios y necesidades" 10 . En ese contexto, tanto la CADH como el PIDCP consagran la garantía del derecho al recurso restringida al ámbito de la justicia criminal.

Acerca del particular, el artículo 8 numeral 2 de la CADH y el artículo 14.5 del PIDCP en sus partes pertinentes expresan lo siguiente, respectivamente:

“Artículo 8. Garantías Judiciales

2. Toda persona inculpada de delito tiene derecho a que se presuma su inocencia mientras no se establezca legalmente su culpabilidad. Durante el proceso, toda persona tiene derecho, en plena igualdad, a las siguientes garantías mínimas:

h. derecho de recurrir del fallo ante juez o tribunal superior".

\section{"Artículo 14}

5. Toda persona declarada culpable de un delito tendrá derecho a que el fallo condenatorio y la pena que se le haya impuesto sean sometidos a un tribunal superior, conforme a lo prescrito por la ley".

El tenor literal de ambos preceptos dispone su naturaleza y ámbito de aplicación eminentemente penal, cuestión que se ve refrendada por su ubicación sistemática dentro de cada uno de los instrumentos recién referidos.

Adicionalmente, toda la jurisprudencia que los defensores del derecho al recurso en sede civil citan para sostener su posición, guarda relación con causas de tipo sancionatorio o derechamente penal. "Posteriormente, la Corte Interamericana ha seguido extendiendo el contenido del debido proceso a materias no penales de carácter sancionatorio (...) Pero nunca en su jurisprudencia se ha referido de forma específica a la extensión o aplicación del derecho a recurrir a juicios de carácter civil. Por otra parte, toda la jurisprudencia específica donde se ha desarrollado el derecho al recurso en el

${ }^{9}$ Por todos ver: Valenzuela, W., Derecho al recurso. Del sistema interamericano a la situación de Chile, EJS, Santiago, 2013, pp. 47 y ss.

${ }^{10}$ Duce, M., Fuentes, C., NúÑez, R. y Riego, C. El derecho a un recurso y el proceso civil. Artículo publicado electrónicamente en El Mercurio Legal, de fecha 18 de diciembre de 2015. Disponible en: http:// www.elmercurio.com/Legal/Noticias/Redes/Detallenoticia.aspx?id=904422. En el mismo sentido, Bordalí en: Bordalí, A., Cortés, G. y Palomo, D., Proceso civil. El juicio ordinario de mayor cuantía, procedimiento sumario y tutela cautelar, Thomson Reuters, Santiago, 2014, p. 47. 
sistema interamericano de protección de derechos humanos, como los fallos Herrera Ulloa contra Costa Rica, Mohamed contra Argentina y Norín Catriman contra Chile, se ha referido a casos penales"11.

En cuanto al PIDCP, el Comité de Derechos Humanos de las Naciones Unidas que es el órgano que supervisa la aplicación de dicho pacto por sus Estados Partes ${ }^{12}$, en diversas ocasiones ha tenido ocasión de pronunciarse acerca del contenido del mentado artículo $14 \mathrm{~N}^{\circ} 5$. En ese orden de cosas, "en la comunicación $\mathrm{N}^{\circ}$ 450/1991 contra Finlandia resuelta en 1993, el Comité estableció que el derecho a recurrir estaba limitado al ámbito penal" ${ }^{13}$. Luego, en el 2007 por medio de su Observación General Nº 32, el Comité ratificó su posición y excluyó expresamente a los procesos civiles de la aplicación del artículo $14 \mathrm{~N}^{\circ} 5$ del PIDCP, por cuanto el "párrafo 5 del artículo 14 no se aplica a los procedimientos para determinar los derechos y obligaciones de carácter civil ni a ningún otro procedimiento que no forme parte de un proceso de apelación penal, como los recursos de amparo constitucional"14-15-16.

Por último, en reciente jurisprudencia del Excmo. Tribunal Constitucional se ha ratificado plenamente lo que viene ocurriendo en el contexto internacional, esto es, que el derecho al recurso sí se encuentra consagrado expresamente para los procesos penales, pero "respecto de la materia civil o de cualquier otro carácter, solo rige el estatuto general de ser juzgado por un tribunal idóneo 'con las debidas garantías', de manera que la ausencia o falta de existencia o de acceso a un recurso existente puede ser compensada con la presencia o fortalecimiento de otras garantías. En suma, es un asunto que se remite a la competencia del legislador nacional"17. A mayor abundamiento, el Excmo. Tribunal resumió el derecho al recurso en el proceso civil como sigue:

“(...) la norma constitucional en materia de derecho al recurso en asuntos civiles puede enunciarse así: la Constitución no asegura el derecho al recurso per se, remitiendo su regulación al legislador, quien, soberanamente, podrá establecerlos como ordinarios o extraordinarios, quedando solo desde entonces integrados al debido proceso, con sus excepciones. Pero tal regulación solo será constitucional cuando impida o restrinja el acceso al recurso legalmente existente sobre la base de criterios de razonabilidad y proporcionalidad, es decir, para perseguir un fin constitucionalmente legítimo (protección de otros derechos o valores), con mínima

${ }^{11}$ Duce, M., Fuentes, C., Núñez, R. y Riego, C., El derecho a un recurso y el proceso civil, ob. cit.

${ }^{12}$ Véase las funciones del Comité de Derechos Humanos en: http://www2.ohchr.org/spanish/bodies/hrc/

13 Duce, M., Fuentes, C., NúÑez, R. y Riego, C., El derecho a un recurso y el proceso civil, ob. cit.

${ }^{14}$ Comité de Derechos Humanos de las Naciones Unidas. Observación General No 32, de fecha 23 de agosto de 2007. Disponible en: http://www1.umn.edu/humanrts/hrcommittee/S-gencom32.pdf

${ }^{15}$ En el mismo sentido, véase el Considerando Decimoséptimo de la Sentencia del Excmo. Tribunal Constitucional, Rol 2798-15-INA, de fecha 24 de diciembre de 2015.

${ }^{16}$ Consejo de Europa. Guide to Article 6, Right to a Fair Trial, pp. 19-23. Disponible en: http://www. echr.coe.int/Documents/Guide_Art_6_ENG.pdf

${ }^{17}$ Véase especialmente los Considerandos Decimosexto al Trigésimo primero de la Sentencia del Excmo. Tribunal Constitucional, Rol 2798-15-INA, de 24 de diciembre de 2015. 
intervención o afectación del derecho a defensa (esto es, sin suprimir la defensa, sino compensándola con otros derechos, recursos o medidas o, incluso, con la sola jerarquía e integración del tribunal, dentro de un diseño procesal específico, concentrado e inmediato)" 18 .

Por consiguiente, es improcedente sostener la existencia de un derecho al recurso en el proceso civil chileno, pues ello carece de raigambre normativa y jurisprudencial tanto a nivel del derecho interno chileno como del derecho internacional vigente y ratificado por Chile.

Por tanto, no cabe sino concluir que "la decisión sobre la estructura y forma de los medios por los cuales se hace efectiva la revisión de sentencias corresponde -en principio-al legislador" ${ }^{19}$, cuestión aplicable a los recursos en el proceso civil y, en particular, el recurso de apelación. En abono de esta posición, tampoco podemos pasar por alto los nuevos parámetros de la justicia civil a nivel internacional, en el sentido que existe "una tendencia internacional de restringir los recursos en materia civil, considerando las garantías del proceso civil contemporáneo: oralidad, inmediación, posibilidad de decretar prueba de oficio, etcétera." ${ }^{20}$.

De esta forma, como se verá más adelante, resulta admisible en el proceso civil mecanismos de discrecionalidad reglada ex post que limiten la procedencia de ciertos recursos, permitiendo que los tribunales superiores afecten la expectativa que un litigante pudiera tener acerca de la revisión efectiva de su recurso.

III. El RÉGIMEN DE APELACIÓN EN EL PROCESO CIVIL CHILENO:

UN EJEMPLO DE COMPATIBILIZACIÓN ENTRE DEBIDO PROCESO Y EFICIENCIA, A PROPÓSITO DE LA INADMISIBILIDAD ANTE EL TRIBUNAL SUPERIOR

\section{Introducción}

Las consideraciones respecto del factor tiempo son relevantes en el ámbito de los recursos. Por lo mismo, se han elaborado y desarrollado ciertos instrumentos procesales tendientes a evitar los efectos perniciosos del transcurso del tiempo en lo que se refiere al ámbito recursivo.

Una clase de estos instrumentos mira a la forma en cómo son concedidos los recursos, encontrando allí el efecto inmediato de las sentencias judiciales.

18 Véase el Considerando Trigésimo primero de la Sentencia del Excmo. Tribunal Constitucional, Rol 2798-15-INA, de 24 de diciembre de 2015.

19 Véase el Considerando Vigésimo primero de la Sentencia del Excmo. Tribunal Constitucional, Rol 2853-15-INA, de 24 de diciembre de 2015. En el mismo sentido, véanse las Sentencias del Excmo. Tribunal Constitucional, Roles No $1373,1432,1443$ y 1535).

${ }^{20}$ Núñez OJeda, R. y Peréz Ragone, Á., ob. cit., p. 17. 
Otro grupo de instrumentos viene dado por aquellos mecanismos que pretenden reducir el nivel de recursos que el sistema genera, en términos tales, que sea factible recurrir solamente en aquellos casos en que es deseable la revocación. Lo anterior hace necesario el establecimiento de filtros que impidan que todas las decisiones puedan ser recurridas sin que exista un fundamento serio que sustente dicha posibilidad, o bien que el costo de esos recursos no compense sus beneficios.

Sin embargo, estos instrumentos están afectos a problemas. La primera clase de instrumentos está afecta a la posibilidad de que el ganancioso no desee ejecutar la decisión frente al riesgo de la revocación, por mínima que esta sea. Es un escenario normal, toda vez que la mayoría de los litigantes son adversos al riesgo y, en consecuencia, no querrán enfrentar una posible ejecución que luego fracase por la posibilidad de revocación. Por lo mismo es que incluso aquellas sentencias definitivas que en el sistema chileno causan ejecutoria, no son ejecutadas sino hasta que adquieren el estado de firmes y ejecutoriadas ${ }^{21}$.

La segunda clase de instrumentos enfrentan la gran problemática relativa a la satisfacción de estándar de debido proceso, en su faceta de derecho al recurso.

Con todo, en el caso chileno y a propósito de un recurso extraordinario en el proceso civil -recurso de casación en el fondo-, el legislador procesal civil ha entendido satisfecho dicho estándar cuando existe declaración de inadmisibilidad por manifiesta falta de fundamento, como se extrae de la configuración adoptada en el artículo 782 del Código de Procedimiento Civil $^{22}$ (que procede de la última gran reforma legal al recurso de casación contenida en la Ley $\mathrm{N}^{\circ} 19.374$ de 1995). Entonces se formula la siguiente pregunta: ¿es conveniente extender dicha inadmisibilidad prevista expresamente por el legislador a recursos ordinarios ${ }^{23}$ ? Ello parecería apropiado, máxime si estos recursos pueden ser sostenidos sin necesidad de requisitos formales, lo que favorece la litigación estratégica a su respecto.

Es allí donde la eficiencia tiene mucho que aportar en la búsqueda de una eficiente regulación procesal. Ello vendrá dado por entender la administración de justicia como

${ }^{21}$ Véase: Meneses Pacheco, C. "La ejecución provisional en el proceso civil chileno”. Revista Chilena de Derecho, Vol. 36 N 1, pp. 21-50. Disponible electrónicamente en: http://www.scielo.cl/scielo.php?script=sci_ar ttext\&pid=S0718-34372009000100003.

22 “Artículo 782.- Elevado un proceso en casación de fondo, el tribunal examinará en cuenta si la sentencia objeto del recurso es de aquellas contra las cuales lo concede la ley y si este reúne los requisitos que se establecen en los incisos primeros de los artículos 772 y 776.

La misma sala, aun cuando se reúnan los requisitos establecidos en el inciso precedente, podrá rechazarlo de inmediato si, en opinión unánime de sus integrantes, adolece de manifiesta falta de fundamento.

Esta resolución deberá ser, a lo menos, someramente fundada y será susceptible del recurso de reposición que establece el inciso final del artículo 781.

En el mismo acto el tribunal deberá pronunciarse sobre la petición que haya formulado el recurrente, en cuanto a que el recurso sea visto por el pleno de la Corte Suprema, de conformidad a lo establecido en el artículo 780. La resolución que deniegue esta petición será susceptible del recurso de reposición que se establece en el inciso final del artículo 781.

Es aplicable al recurso de casación de fondo lo dispuesto en los incisos segundo, tercero y cuarto del artículo $781 ”$.

${ }^{23}$ De acuerdo con la clasificación de los mismos, relativa a la causal que hace procedente el recurso. 
un servicio público financiado con rentas generales que debe generar externalidades positivas, esto es, decisiones que permitan a las personas y a los jueces tener un lineamiento de la decisión que, según sus más altos tribunales, debería regir en un caso particular.

En este sentido, la causal de inadmisibilidad mencionada puede ser mejorada si es que vinculamos la manifiesta falta de fundamento con un control que examine si el recurso en cuestión estará en condiciones -en el evento de ser resuelto favorablemente para el apelado-, de cooperar en la búsqueda de tales externalidades positivas.

Tal mecanismo, sin embargo, debe ser establecido entre dos umbrales de riesgo. El primero, que denominaremos umbral mínimo de riesgo, es evitar que el trámite de la inadmisibilidad conduzca a consagrar un régimen de única instancia, cuyo gran vicio en términos de eficiencia es favorecer la litigación del propenso al riesgo, y; el segundo, que llamaremos: umbral máximo de riesgo, pretende evitar que el trámite de inadmisibilidad impida la búsqueda de las externalidades públicas positivas, toda vez que esto último se alcanza únicamente por medio del fallo sobre el fondo del recurso. Por tanto, el propósito es que tales umbrales influyan en los jueces de instancia como un control de las decisiones que éstos adoptan, las que debiesen ser conformes a las directrices, reglas o principios generales que emanan de las mencionadas externalidades.

\section{Nuevamente el tiempo como problema: a propósito del sistema recursivo}

Uno de los factores que inciden en que la respuesta jurisdiccional no sea lo suficientemente oportuna dice relación con que la construcción de la decisión jurisdiccional contempla, por regla general, la existencia de dos instancias ${ }^{24}$. Lo anterior significa en el vocabulario jurídico habitual dos grados de conocimiento de un asunto en los hechos y en el derecho por parte de tribunales distintos y de diferente jerarquía ${ }^{25}$. Lo anterior, en términos tales que el tribunal de superior jerarquía revisa la decisión de aquel de inferior jerarquía.

${ }^{24} \mathrm{La}$ instancia es cada uno de los grados de conocimiento y fallo de que está investido un tribunal para la solución de un determinado conflicto, encontrándose, dentro de cada instancia, facultado para resolver todas las cuestiones de hecho y de derecho que se susciten en el juicio. El concepto de instancia, en el derecho chileno, fluye de los artículos 188 y 189 del Código Orgánico de Tribunales, vinculando la instancia al recurso de apelación, de modo que: i) un asunto se falla en única instancia cuando la resolución del tribunal no puede ser apelada; ii) un asunto se falla en primera instancia cuando en contra del fallo procede la interposición del recurso de apelación, y; iii) la segunda instancia es el conocimiento y fallo por el tribunal superior jerárquico de la apelación interpuesta. Maturana, C. y Mosquera, M., Los Recursos Procesales, Editorial Jurídica de Chile, Santiago, 2010, p. 80. En el mismo sentido, véase Núñez, R. y Pérez-Ragone, Á., Manual de Derecho Procesal Civil, Los medios de impugnación, ob. cit., 2015, pp. 83 y siguientes.

${ }^{25}$ Ronald Coase, al tratar el problema del costo social, expresa que el costo de ejercitar un derecho es asimilable a la ejecución de un factor de producción, de modo tal que el costo de ese ejercicio siempre consiste en la pérdida que sufre la contraparte como consecuencia del ejercicio del derecho. En atención a ello, es que el criterio de minimización basa su planteamiento en que todas las acciones a desarrollar tuviesen un mayor valor de lo que se perdiese, es decir, bajo un análisis costo-beneficio la ganancia siempre sea superior a la pérdida. CoAse, R., "El problema del Costo Social”, en Revista de Estudios Públicos, 1992 (No 45), pp. 1-44. 
Obviamente que dicha posibilidad de revisión por otro tribunal superior supone el establecimiento de un costo terciario temporal, consistente en el tiempo que demora la revisión. Dicho costo se ahorraría si es que dicha posibilidad dejara de existir. Lo anterior podría ser la materialización de una política judicial que basada en eficiencia tienda a minimizar costos -siguiendo criterios cercanos al concepto de eficiencia de Coase $^{26}$-; sin embargo, exigencias de debido proceso imponen la necesidad de algún grado de conocimiento del asunto por un tribunal superior.

Pues bien, la decisión normativa de los distintos sistemas jurídicos -y el caso chileno no es la excepción - ha sido contemplar la posibilidad de revisión en una segunda instancia, basado en la lógica que la corrección de los costos del error del juez de primera instancia supera en beneficios a los costos que pudieran derivarse de un mecanismo de única instancia, que como hemos visto, suponen costos administrativos.

Por lo mismo es que el problema del tiempo va estrechamente ligado al fenómeno recursivo.

Antes de continuar es necesario clarificar conceptualmente que cuando nos referimos al concepto de instancia, estamos hablando del recurso que típicamente permite la existencia de la doble instancia, esto es, el recurso de apelación ${ }^{27}$. Ello es importante de ser clarificado, toda vez que la problemática que luego se desarrollará se plantea precisamente respecto de recursos de reforma como es el recurso de apelación, donde por medio de la concurrencia de un simple agravio formal es posible plantear una nueva discusión en los hechos y en el derecho. En otras palabras, respecto de recursos donde se pueda plantear mayor nivel de litigación, es donde se genera con mayor probabilidad la concurrencia de costos administrativos, ya que en principio los requisitos para alegar su inadmisibilidad son menores.

\section{Instrumentos para afrontar la problemática temporal en materia recursiva}

Es posible precisar que a pesar de la existencia de consideraciones de debido proceso a favor del establecimiento de una revisión por un tribunal superior de la decisión adoptada por uno inferior, de todas formas el legislador procesal ha establecido diversos mecanismos tendientes a evitar el extremo nocivo que un régimen de recursos - de retracto amplio- pudiera producir. Dichos efectos nocivos van asociados al denominado

${ }^{26}$ Ver: (i) CoAse, R., "El problema del Costo Social", en Revista de Estudios Públicos. 1992, N 45, p. 3, y (ii) Beyer, H., "Ronald Coase y su contribución a la teoría de la economía y del derecho". Revista de Estudios Públicos, 1992, No 45, p. 12.

${ }^{27}$ En su definición normativa, el artículo 186 del Código de Procedimiento Civil lo define diciendo: "El recurso de apelación tiene por objeto obtener del tribunal superior respectivo que enmiende, con arreglo a derecho, la resolución del inferior.

Por otra parte, los profesores Mosquera y Maturana lo han definido como "el acto jurídico procesal de la parte agraviada, o que ha sufrido un gravamen irreparable con la dictación de una resolución judicial, por medio del cual solicita al Tribunal que la dictó que eleve el conocimiento del asunto al Tribunal superior jerárquico, con el objeto que este la enmiende con arreglo a derecho”. Maturana, C. y Mosquera, M., ob. cit., p. 120. 
"efecto suspensivo" 28 , esto es, que la decisión del tribunal inferior no pueda ser llevada a efecto sino cuando la decisión haya sido confirmada por el tribunal superior. Al respecto, dichos efectos nocivos concurren, toda vez que, en estos casos, se maximiza la demora en el proceso porque la decisión confirmatoria de la segunda instancia es un presupuesto necesario de la ejecución.

Dichos mecanismos de ajuste al efecto suspensivo corresponden a su efecto contrario, esto es, el denominado "efecto devolutivo" ${ }^{29}$, que permite que las decisiones puedan ser ejecutadas a pesar de la existencia de una segunda instancia, salvo que el tribunal superior decrete una orden de no innovar u otra medida suspensiva ex post (por contraposición, a la paralización ex ante de la competencia del tribunal inferior que opera por el efecto suspensivo).

En el caso chileno, el legislador contempló en sus inicios como regla general el efecto suspensivo. Con todo, mediante sucesivas reformas, fue consagrando supuestos de efecto devolutivo, siendo hoy la regla general que las apelaciones sean concedidas en este último efecto ${ }^{30}$.

${ }^{28}$ En su definición normativa, el artículo 191, inciso primero, del Código de Procedimiento Civil, lo define expresando: "Cuando la apelación comprenda los efectos suspensivo y devolutivo a la vez, se suspenderá la jurisdicción del tribunal inferior para seguir conociendo de la causa".

Asimismo, los profesores Mosquera y Maturana lo han definido como "aquel en virtud del cual se suspende la competencia del Tribunal inferior para seguir conociendo de la causa, no pudiendo cumplirse la resolución impugnada hasta que no sea resuelto el recurso interpuesto en su contra" MaturanA, C. y Mosquera, M., ob. cit., p.149. Para el profesor Couture el asunto se centra en "cuanto al efecto suspensivo de la apelación consiste en el enervamiento provisional de los efectos de la sentencia, una vez introducido el recurso de apelación”. Couture, E., Fundamentos del Derecho Procesal Civil, Thomson Reuters, Santiago, 2010 , p. 371.

${ }^{29}$ En su definición normativa, el artículo 192, inciso primero, del Código de Procedimiento Civil, lo define expresando: "Cuando la apelación proceda solo en el efecto devolutivo, seguirá el tribunal inferior conociendo de la causa hasta su terminación, inclusa la ejecución de la sentencia definitiva”.

En el ámbito doctrinal, los profesores Mosquera y Maturana lo han definido como "aquel en virtud del cual se otorga competencia al Tribunal superior jerárquico para conocer y fallar el recurso de apelación deducido en contra de la resolución pronunciada por el Tribunal inferior, pudiendo resolver acerca de la reforma o enmienda del fallo impugnado”. Maturana, C. y Mosquera, M., ob. cit., p. 148. Por otro lado, Couture lo define al decir que "Por efecto devolutivo se entiende, a pesar del error en que puedan hacer incurrir las palabras, la remisión del fallo apelado al superior que está llamado, en el orden de la ley, a conocer de él”. Couture, E., ob. cit., p. 368.

${ }^{30}$ La norma decisiva del Código de Procedimiento Civil para reflejar esta situación es el artículo 194, cuya evolución denota la ampliación del efecto devolutivo en el proceso de apelación chileno. Así, el Código de Procedimiento Civil primigenio publicado en 1902, en el entonces artículo 217 -actual 194- disponía: "Sin perjuicio de las escepciones espresamente establecidas en la lei, se concederá apelación solo en el efecto devolutivo: $1 .^{\circ}$ De las resoluciones dictadas contra el demandado en los juicios ejecutivos i sumarios; $2 .^{\circ} \mathrm{De}$ los autos i decretos cuyos resultados serían eludidos, admitiéndose apelación en ambos efectos; $3 .^{\circ}$ De las resoluciones pronunciadas en el incidente sobre ejecución de una sentencia firme, definitiva o interlocutora; i $4 .^{\circ}$ De todas las demás resoluciones que por disposición de la lei solo admitan apelación en el efecto devolutivo". La Ley N 18.705 de 1988 vino a cambiar la situación, consagrando el texto del actual artículo 194 que extiende la procedencia del efecto devolutivo al decir: "Sin perjuicio de las excepciones expresamente establecidas en la ley, se concederá apelación en el solo efecto devolutivo: $1 .^{\circ}$ De las resoluciones dictadas contra el demandado en los juicios ejecutivos y sumarios; $2 .^{\circ}$ De los autos, decretos y sentencia interlocutora; 
Una nueva etapa en dicho tránsito ha sido la introducción del concepto de sentencias de ejecución inmediata, que se consagra en el Proyecto de Nuevo Código Procesal $\mathrm{Civil}^{31}$, que se tramita actualmente en el Congreso Nacional de Chile. Por intermedio de tal instrumento procesal, la regla general será que las resoluciones judiciales causen ejecutoria y, por tanto, puedan ser cumplidas aún existiendo recursos pendientes.

\subsection{Motivos por los que estos instrumentos no son apropiados}

Sin embargo, las resoluciones a pesar de que en su contra se haya interpuesto apelación y esta haya sido concedida en el solo efecto devolutivo y, por tanto, puedan ser ejecutadas, de todas formas, en la práctica, no lo son, sino hasta cuando existe sentencia confirmatoria por el tribunal superior.

A pesar de que no existen datos cuantitativos que permitan corroborar dicha hipótesis, ello emana de la práctica misma del sistema judicial chileno.

Las razones de ello emanan de la posición frente al riesgo que poseen la mayoría de los litigantes, cual es: personas con aversión al riesgo. En este sentido, en el proceso intervienen personas que se vinculan con el riesgo de manera similar a cómo tales personas intervienen en el resto de sus ámbitos de relación. Así, para el AED la regla general es que las personas sean adversas al riesgo, y no neutrales o propensas.

Consecuencia natural de dicha característica es que las personas tenderán a litigar proporcionalmente menos que una persona neutral y, mucho menos aún, que una persona propensa $^{32}$. De esta forma, para tales personas la existencia de una posibilidad de revocación -por muy poco probable que sea- hace más valorable la situación que preexiste al probable fallo confirmatorio -escenario sin ejecución-; que una eventual situación donde se deba deshacer lo realizado -escenario con ejecución- en el marco de un fallo revocatorio por el juez superior.

A ello se suma que la ley ha contemplado como presupuesto normativo de los mecanismos de suspensión ex post la imposibilidad de deshacer lo ejecutado ${ }^{33}$. Con ello,

3. De las resoluciones pronunciadas en el incidente sobre ejecución de una sentencia firme, definitiva o interlocutoria; $4 .^{\circ}$ De las resoluciones que ordenen alzar medidas precautorias; y $5 .^{\circ}$ De todas las demás resoluciones que por disposición de la ley solo admitan apelación en el efecto devolutivo”.

${ }^{31}$ Regulada en el Título VII, Capítulo $4^{\circ}$, Subpárrafo $2^{\circ}$ del Proyecto de Código Procesal Civil, artículo 234 que dispone: "Las sentencias definitivas de condena, una vez notificadas a todas las partes, podrán ser cumplidas provisionalmente conforme a las disposiciones siguientes".

${ }^{32}$ Para el AED las personas que se encuentran en un proceso judicial pueden ser clasificadas en litigantes adversos, neutros o propensos al riesgo, cuestión que es determinante para configurar una teoría de la litigación. En este sentido, estas personas al encontrarse ante la decisión de ejecutar una sentencia que aún se encuentra pendiente de confirmación, afronta el dilema como una elección entre la ganancia segura de ejecutar una vez confirmada la sentencia y la ganancia probabilística de ejecutar una sentencia que eventualmente puede ser revocada. Bajo estas condiciones, juega un papel fundamental el cómo la persona en cuestión concibe al riesgo: neutro, adverso o propenso. Para mayor información, consultar: RACHLINSKI, J., "Gains, Losses, and the Psychology of Litigation", en California Law Review, vol. 70, 1996, p. 113.

${ }^{33}$ El Código de Procedimiento Civil chileno contempla una normativa acerca de la orden de no innovar que se produjo con la publicación de la Ley $\mathrm{N}^{\circ} 18.705$, la que tuvo como antecedente una anterior ampliación 
la recomendación razonable frente a la ejecución es no llevarla a cabo completamente, pendiente que estén los recursos, precisamente porque de llevar a cabo la ejecución de manera completa, permitirán la alegación de suspensión ex post (orden de no innovar).

Lo anterior incluso se ve como más probable cuando la suspensión ex post está regulada como una petición no estratégica, esto es, donde existe una sola oportunidad para pedir dicha suspensión bajo riesgo de preclusión. Dicha regulación existe en la fianza de resultas ${ }^{34}$, donde la posibilidad de transformar un recurso que cause ejecutoria en uno que no produzca dicho efecto, se concentra al momento de deducir el recurso en cuestión. De esta forma, como los litigantes saben que no tendrán una nueva oportunidad para realizar tal petición, entonces siempre tendrán los incentivos para pedir la fianza de resultas, transformándose los efectos de esos recursos desde un sistema devolutivo que permite la ejecución en el intertanto, a un sistema propiamente suspensivo.

\section{Mecanismos de inadmisibilidad en el proceso civil}

Pues bien, otra posibilidad normativa de evitar los efectos nocivos del sistema recursivo respecto de los costos administrativos que la revisión de un superior puede generar, viene dada no por la alternativa de adelantar la ejecución en el intertanto de la decisión -aspecto discutido en la sección anterior-, sino que por medio de consagrar mecanismos procesales tendientes a que el tribunal superior, con mayor o menor grado de discreción, pueda definir qué recursos serán finalmente decididos.

de los casos en que la apelación procedía en el solo efecto devolutivo. En este orden de cosas, el artículo 192 , incisos segundo y tercero, establecen: "No obstante, el tribunal de alzada a petición del apelante y mediante resolución fundada, podrá dictar orden de no innovar. La orden de no innovar suspende los efectos de la resolución recurrida o paraliza su cumplimiento, según sea el caso. El tribunal podrá restringir estos efectos por resolución fundada. Los fundamentos de las resoluciones que se dicten de conformidad a este inciso no constituyen causal de inhabilidad. Las peticiones de orden de no innovar serán distribuidas por el Presidente de la Corte, mediante sorteo, entre las salas en que esté dividida y se resolverán en cuenta. Decretada una orden de no innovar, quedará radicado el conocimiento de la apelación respectiva en la sala que la concedió y el recurso gozará de preferencia para figurar en tabla y en su vista y fallo”.

${ }^{34}$ A continuación, se indican casos de fianza de resultas dentro del Código de Procedimiento Civil chileno: (i) Artículo 6, inciso tercero: "Podrá, sin embargo, admitirse la comparecencia a juicio de una persona que obre sin poder en beneficio de otra, con tal que ofrezca garantía de que el interesado aprobara lo que se haya obrado en su nombre. El tribunal, para aceptar la representación, calificara las circunstancias del caso y la garantía ofrecida, y fijará un plazo para la ratificación del interesado".; (ii) Artículo 279: "Podrán solicitarse como medidas prejudiciales las precautorias de que trata el Título V de este Libro, existiendo para ello motivos graves y calificados, y concurriendo las circunstancias siguientes: 1. ${ }^{a}$ Que se determine el monto de los bienes sobre que debe recaer las medidas precautorias; y 2. ${ }^{a}$ Que se rinda fianza u otra garantía suficiente, a juicio del tribunal, para responder por los perjuicios que se régimen y multas que se impongan”. (iii) Artículo 773, inciso primero y segundo: "El recurso de casación no suspende la ejecución de la sentencia, salvo cuando su cumplimiento haga imposible llevar efecto o que se dicte si se acoge el recurso, como sería si se tratare de una sentencia que declare la nulidad de un matrimonio o permita el de un menor. La parte vencida podrá exigir que no se lleve a efecto la sentencia mientras la parte vencedora no rinda fianza de resultas a satisfacción del tribunal que haya dictado la sentencia recurrida, salvo que el recurso se interponga por el demandado contra la sentencia definitiva pronunciada en el juicio ejecutivo, en los juicios posesorios, en los de desahucio y en los de alimentos". 
En el sistema procesal civil chileno se reconoce un caso de inadmisibilidad vía discreción ex post. El caso se encuentra contemplado en el artículo 782, inciso segundo, del Código de Procedimiento Civil, a propósito del recurso de casación en el fondo.

Dicha norma señala:

"La misma sala, aun cuando se reúnan los requisitos establecidos en el inciso precedente, podrá rechazarlo de inmediato si, en opinión unánime de sus integrantes, adolece de manifiesta falta de fundamento".

El mencionado supuesto de discrecionalidad está regulado para el caso del recurso de casación en el fondo, que es un recurso extraordinario, que procede solamente con miras a revisar aspectos jurídicos de una decisión (infracción de ley que haya influido sustancialmente en lo dispositivo del fallo ${ }^{35}$ ).

Con todo, los instrumentos de inadmisibilidad de discreción ex post deberían ser más necesarios en recursos ordinarios que comprenden la revisión de aspectos fácticos y jurídicos, toda vez que su activación y procedencia depende exclusivamente de una exigencia puramente formal: el agravio. Esta última exigencia es de tan escasa entidad que prácticamente todas las apelaciones son admitidas para ser conocidas en segunda instancia, de forma que tal recurso necesariamente va asociado a la producción de mayores costos administrativos ${ }^{36}$.

La conceptualización del agravio como la diferencia entre lo pedido y lo declarado ${ }^{37}$ permite que existan apelaciones en que únicamente esté en consideración la posición estratégica de la parte respectiva. Ello, por cuanto la procedencia de la apelación tiende a permitir una segunda revisión sin otra exigencia que revisar aquella parte no concedida por el juez inferior, en circunstancias que la pretensión -aquello pedido- es definida

${ }^{35}$ A estos efectos, el artículo 767 del Código de Procedimiento Civil, que consagra la procedencia de la casación en el fondo, expresa: "El recurso de casación en el fondo tiene lugar contra sentencias definitivas inapelables y contra sentencias interlocutorias inapelables cundo ponen término al juicio o hacen imposible su continuación, dictadas por Cortes de Apelaciones o por un tribunal arbitral de segunda instancia constituido por árbitros de derecho en los casos en que estos árbitros hayan conocido de negocios de la competencia de dichas Cortes, siempre que se hayan pronunciado con infracción de ley y esta infracción haya influido substancialmente en lo dispositivo de a sentencia".

${ }^{36}$ Un sistema con un control mínimo del presupuesto de admisibilidad que habilita la apelación no permite desincentivar a los litigantes que apelan pero que no son víctimas de error, ver SHAVELL, S., "The Appeals Process as a means of error correction", en Journal of Legal Studies, 1995 (Vol. 24, No 2), pp. 379426. Esto podría conducir a un sesgo jurisprudencial prodemandantes-apelantes, ver LuPPI, B, y PARISI, F, "Judicial Creativity and Judicial Errors: and organizational perspective", en Journal of Institutional Economics, 2010 (Vol. 6, N 1), pp. 91-98. Criticando la existencia de una categoría de apelantes víctimas de error y una de aquellos que no lo son, en razón de que los tribunales superiores no tienen manera racional de inferir cuándo estamos en presencia de ambas categorías, se pronuncia Schwartz, E., "A Comment on: The Appeals as a Means of Error Correction. By Steven Shavell”, en Legal Theory, 1995 (Vol. 1, No 3), pp. 361-363.

${ }^{37} \mathrm{La}$ doctrina ha definido el agravio como: "cuando no se obtiene todo lo que se ha pedido en el proceso. En otras palabras, una resolución causará agravio a una parte cuando esta le ha sido desfavorable por no haberse acogido íntegramente las pretensiones o defensas hechas valer por ella en el proceso". MATURANA, C. y Mosquera, M., ob. cit., p. 25. 
individualmente sin límite alguno -salvo extremos de admisibilidad, como la ineptitud del libelo-.

Sostendremos, en lo que sigue, que una de las formas de conducir a la solución del problema temporal es por medio de mecanismos de discrecionalidad ex post aplicables a recursos de revisión fáctica y jurídica, con énfasis en la apelación. Para ello nos basamos en las consideraciones precedentemente señaladas, como también en aquellas que provienen de consideraciones de eficiencia.

En efecto, el AED entrega pautas de escenarios donde dicha posibilidad de discreción ex post resulta admitida ${ }^{38}$.

Para comenzar con el tratamiento de este punto, bajo un contexto de discreción y en el que se reciben apelaciones, el beneficio social de la discreción judicial radica en que la Corte posee la facultad para descartar procesos de apelación cuando el óptimo social proveniente de ellos tiene un valor inferior al costo de la apelación ${ }^{39}$. Así, revisando los costos del proceso de apelación, la Corte se encuentra en posición para rechazar apelaciones que socavan el bienestar social de óptimo de costos.

El presupuesto anterior se demuestra en la siguiente fórmula:

$$
w\left(d *_{s}\right)-w(d)<2 c
$$

En la zona izquierda de la ecuación se halla representado el incremento en el beneficio social si la apelación es tramitada, mientras que en el sector derecho de la ecuación se ubica el costo del proceso de apelación que, al estar compuesto por dos litigantes -apelante y apelado- debe multiplicarse por dos.

Por otra parte, una apelación debe ser admitida a tramitación, si y solo si, el beneficio social del proceso de apelación es superior o igual al costo que implica el procesamiento de la apelación ${ }^{40}$. En términos gráficos ello ocurre cuando:

$$
w\left(d *_{s}\right)-w(d) \geq 2 c
$$

${ }^{38}$ El desarrollo de las fórmulas económicas y su detallada explicación se encuentra en el trabajo de Steven Shavell, titulado: SHAvelL, S., "The Appeals Process and Adjudicator Incentives", en Journal of Legal Studies, 2006, (Vol. 35), pp. 1-29.

${ }^{39}$ Una propuesta más reciente de Shavell acerca del uso de discrecionalidad en la apelación se contiene en Shavell, S., "On the Design of the Appeals Process: The Optimal Use of Discretionary Review versus Direct Appeal”, en Journal of Legal Studies, 2010 (Vol. 39, N 1), pp. 63-108, donde señala que un sistema de discrecionalidad es socialmente deseable cuando la probabilidad de éxito de una apelación (probabilidad de éxito de revocación) se encuentra en un punto medio entre dos umbrales. Debido a que una apelación directa será socialmente deseable cuando supere el segundo umbral, tendremos que un sistema de discrecionalidad debería ser un régimen más habitual que el de apelación directa. Esos umbrales son una función de cálculo de diversos factores, como la probabilidad ex ante de revocación, las probabilidades de éxito del apelante, el beneficio social de la apelación, y el costo de la apelación, ver SHAVELL, S., ob. cit., 2010, pp. 70-75. Sin embargo, se considera que el cálculo de esos umbrales hace inaplicable la fórmula en un sistema como el nacional.

${ }^{40}$ Esto es reiterado en Shavell, cuando señala que la inversión en un sistema de apelación solamente se justifica cuando el error puede ser corregido a un bajo costo, ver SHAVELL, S., ob. cit., 1995, pp. 391-396. 
Considerando estas pautas de AED, surge la pregunta de si restringir la procedencia de un recurso y, por tanto, la revisión de un asunto por un tribunal superior es atentatorio a las exigencias de debido proceso.

Para ello, a continuación, examinaremos las consideraciones que emanan del debido proceso en relación con el régimen de apelación en el proceso civil. Ello nos permitirá responder la cuestión de si resultaría posible sostener la incorporación de consideraciones de eficiencia en la discusión relativa a generar espacios de discrecionalidad en la revisión de la apelación, con la finalidad de reducir costos administrativos. Kaplow y Shavell han indicado la necesidad que cualquier ponderación entre eficiencia y justicia (debido proceso) debe especificar el mecanismo por el que se resuelve la tensión entre una mayor exactitud (impuesta por consideraciones de justicia) y el aumento de costos que ello implica (consideración de eficiencia) ${ }^{41}$. Esa ponderación es la que se busca alcanzar en la propuesta planteada en este artículo.

4.1. ¿Qué consideraciones de debido proceso existen respecto del sistema recursivo en el proceso civil?

Para efectos de estas consideraciones de debido proceso en el proceso civil, damos por reproducida la argumentación ya vertida en el Capítulo 2 del presente trabajo.

Consecuentemente, las menores exigencias de debido proceso respecto de la procedencia del derecho al recurso en el proceso civil, permiten establecer mecanismos que limiten el conocimiento de tal recurso por un tribunal superior. En este sentido, es posible concluir que los mecanismos de inadmisibilidad de discrecionalidad ex post son un ejemplo de técnica legislativa que resulta apropiada en términos de debido proceso.

Lo relevante es que dichos mecanismos de discrecionalidad tienen un fundamento económico, que proviene del AED que hemos señalado precedentemente.

Así, únicamente queda por detallar esos fundamentos, considerando sus límites y restricciones, con miras a proponer una regulación de instrumentos de discrecionalidad ex post fundados en consideraciones de debido proceso y que, simultáneamente, satisfaga exigencias de debido proceso.

\section{Criterios de eficiencia aplicados a la inadmisibilidad vía discrecionalidad ex post}

Hemos revisado los fundamentos económicos de los mecanismos de inadmisibilidad vía discrecionalidad ex post. También hemos señalado por qué dichos mecanismos satisfacen exigencias de debido proceso y permiten alcanzar una mejor solución para la problemática temporal que el estado de los instrumentos procesales ex ante.

${ }^{41}$ Kaplow, L., y Shavell, S., Fairness versus Welfare, Harvard University Press, Cambridge, 2002, pp. 250-254. Para una revisión de la tensión y relación inversa entre aumento de exactitud de las decisiones y costos del sistema, puede verse Carrasco, Nicolás, "La eficiencia procesal y el debido proceso", en Revista de Derecho Privado, 2017 ( $\mathrm{N}^{\circ} 32$ ), pp. 443-469. 
Procede ahora que nos dediquemos a conocer cuáles son los límites o umbrales en los que debería encontrarse la regulación de la inadmisibilidad vía discrecionalidad ex post, en términos de eficiencia.

5.1. No es deseable un sistema de única instancia, ni la pérdida del temor de la apelación

El umbral mínimo dice relación con que el mecanismo de inadmisibilidad vía discrecionalidad ex post no debe conducir a establecer en la práctica un sistema de única instancia. En efecto, por mucho que el sistema de inadmisibilidad contemple un filtro respecto de las apelaciones que se han deducido, ello no puede terminar convirtiendo a la apelación en un recurso imposible por un ejercicio extendido del filtro de inadmisibilidad (umbral mínimo de riesgo).

Así, un sistema de inadmisibilidad administrado por el tribunal superior que actúe con exceso de discrecionalidad en términos de no dar lugar a la tramitación de un gran número de recursos, terminará convirtiendo en la práctica judicial un sistema de doble instancia en uno de única instancia.

Dicha alternativa no resulta deseable, por tres razones económicas:

- El sistema de única instancia promueve la litigación riesgosa: en efecto, planteado el escenario de una decisión en un único juego posible (única instancia), solamente recurrirán al proceso aquellos litigantes que tengan mayor propensión al riesgo, esto es, aquellas personas que litigan proporcionalmente más y con mayor prescindencia de las probabilidades de éxito, ya que apuestan a la probabilidad que posean -lo que permite litigación recursiva en casos que normalmente no ocurrirían-. Y como la opción de decisión se juega en una única oportunidad, dicho litigante tratará de invertir lo mayor posible con miras a maximizar su opción de ganar. Lo anterior no resulta socialmente adecuado, toda vez que conduce a un aumento de los costos administrativos (aumento proporcional al aumento de gastos de inversión en el juicio), y también a un aumento de los costos del error, ante la inexistencia de un escenario de segunda instancia, en donde la posibilidad de equivocación se ve limitada por la doble revisión, y;

- El sistema de única instancia afecta el incentivo del juez inferior para adecuarse a la decisión socialmente óptima o correcta, al destruir la amenaza de la apelación ${ }^{42}$. En efecto, la discreción tiene aptitud para reducir la probabilidad de ocurrencia de apelaciones y con ello incentivar al juez de primera instancia a fallar conforme

${ }^{42}$ Esto evita la existencia de restricciones judiciales frente a la posibilidad de una revocación de las decisiones, ver Drahozal, C., "Judicial Incentives and the Appeals Process", en Southern Methodist University Law Review, 1998 (Vol. 51, N³), pp. 498-499. 
al óptimo $(d * s)^{43}$, esto es, adecuarse a las externalidades que emanan de los tribunales superiores ${ }^{44}$.

- El sistema de única instancia disminuye los incentivos para una salida negociada del conflicto (los acuerdos son una alternativa de menor costo que la revisión de la apelación $)^{45}$. Ello aumenta los costos totales del sistema judicial.

\subsection{Es deseable generar externalidades positivas, tanto respecto de los litigantes} como de los jueces de instancia

La novedad del AED se debe a que introduce la técnica económica moderna al estudio del derecho, pretendiendo dotar a este de eficiencia y de una mirada consecuencialista, desde su perspectiva normativa. El resultado de ello es el tránsito desde la intuición económica del problema jurídico hacia el $\mathrm{AED}^{46}$.

De esta forma, si un juez en el sistema continental de base romanista tiene la posibilidad de optar por la eficiencia ${ }^{47}$ al valorar las consecuencias alternativas que puede generar su decisión, entonces, tendría el ámbito de competencia suficiente para poder aplicar, en su tarea de resolución de escenarios de elección social, la perspectiva normativa del law and economics. Eso supondría que la labor de adjudicación se transforma en la posibilidad del juez de tomar una decisión que signifique otorgar incentivos e información a los individuos para que en casos futuros puedan ajustar su conducta a reglas claras y definidas en precedentes asentados en razón de criterios que incluyan razonamientos económicos.

Como podemos apreciar, entender el sistema de administración de justicia en los términos señalados es lo que permite generar un efecto disuasivo general, produciendo externalidades públicas positivas, que justifiquen el gasto estatal por medio de recursos provenientes de rentas generales. Solamente considerando la labor judicial de manera consecuencialista, mirando hacia el futuro, y preocupándose de la generación de incentivos a los sujetos, aplicando criterios de eficiencia en la resolución de los casos, es que podemos permitir la producción de externalidades públicas positivas, este es el umbral

${ }^{43}$ Desde el momento que el juez de primera instancia resuelve o tiende a resolver conforme al óptimo social contenido en las sentencias de la Corte, pues la apelación se presenta como una amenaza.

${ }^{44}$ Shavell, S., ob. cit., 2006, pp. 21-22.

45 Drahozal, C., ob. cit., p. 498.

${ }^{46}$ Así, hoy el AED si bien reconoce un origen impropio en dichas expresiones de sentido común, resulta forzoso concluir que sus inicios se encuentran vinculados con la economía moderna.

${ }^{47}$ Una posición contraria sostiene Bentham, ya que para él un juez se debe comportar como un utilitarista de la regla, en virtud de ello, debe aplicar las leyes maximizadoras de bienestar emitidas por un legislador utilitario, aunque en un caso concreto ello signifique no incrementar ni maximizar la felicidad, ello porque de acuerdo con la máxima de Bentham el juez siempre debe aplicar las leyes emitidas por el legislador. Desde este punto vista, e impidiendo que la judicatura se comporte como un utilitarista del acto, Bentham estaría cerrando la puerta a una aplicación inmediata de criterios de eficiencia donde el legislador no lo haya contemplado. Así: Moreso, J.J., La teoría del Derecho de Bentham, PPU, Barcelona, 1992, p. 360. Una posición contraria sostiene: Postema, G., Bentham and the Common Law Tradition, Clarendon Press, Oxford, 1986, p. 430. 
máximo de riesgo en que debe estructurarse el instrumento de inadmisibilidad vía discrecionalidad ex post.

Dichas externalidades públicas positivas son aquellas que el sistema recursivo, por intermedio de los jueces superiores, deben resguardar. En este sentido, las consideraciones de eficiencia que hemos examinado nos permiten sostener que las decisiones de los jueces superiores deben velar por la corrección de los fallos de los jueces inferiores a la decisión que se cumple con las externalidades públicas positivas generadas por la aplicación normativa de criterios consecuencialistas.

Aplicando las pautas de eficiencia señaladas precedentemente, podemos señalar que dicha función de vigilante no solamente se deberá cumplir al momento de resolver el recurso, sino que también al momento de declarar la admisibilidad del recurso ante el tribunal superior. De esa manera se permitirá el conocimiento por el juez superior solo de aquellos recursos que tengan un valor relevante en relación con las externalidades públicas positivas existentes, desechándose aquellos recursos cuyo valor en relación con esas externalidades se vea compensado por los costos del proceso de apelación. En otras palabras, si dichos costos superan el valor asociado a la mantención de las externalidades, entonces, debería operar la inadmisibilidad vía discrecionalidad ex post, ya que no se justifica económicamente la tramitación de un recurso cuyo valor social es puramente marginal en términos agregados ${ }^{48}$.

Estando bien definido el supuesto de inadmisibilidad, entonces, el proceso de apelación producirá el efecto socialmente deseado de que el juez inferior tienda a adecuar su decisión a la externalidad pública positiva aplicable. De otra forma, la apelación que se entable en contra de su decisión superará el trámite de la admisibilidad y existirá revocación por parte del tribunal superior ${ }^{49}$.

\footnotetext{
${ }^{48}$ Esto es ratificado por SHAVELL, S., ob. cit., 2010, p. 94, cuando señala que un sistema de apelación sin régimen de discrecionalidad conduce a que las Cortes de apelaciones utilicen tiempo en conocer apelaciones que no generan beneficios sociales.

49 Véase el artículo de Steven Shavell (Shavell, S., ob. cit., 2006, pp. 1-9), donde crea un modelo básico en donde establece que si un juez de primera instancia se encuentra en posición de saber que las partes recurrirán respecto de su sentencia, sus incentivos para generar sentencias no apelables vendrán dados por los criterios óptimos producidos por los jueces superiores. En este contexto, el autor también agrega extensiones al modelo básico, las que permiten enfocar los incentivos del juez inferior hacia el conocimiento de la eficiencia impuesta por los fallos de la Corte (por ejemplo, sistemas de monitoreo de sentencias, subsidios a la apelación y la ya tratada discreción ex post de admisibilidad).

En un sentido similar, los autores Cooter y Ulen exponen que los sistemas judiciales jerárquicos permiten que los jueces superiores vigilen el desempeño de los jueces inferiores y corrijan sus errores a bajo costo. El sistema de apelaciones mantiene bajos los costos de la vigilancia porque los litigantes casi siempre apelan cuando el tribunal inferior comete un error. Por lo tanto, un sistema de apelaciones permite que los jueces superiores conozcan la información privada de los litigantes acerca de si un tribunal cometió un error. COOTER, R. y Ulen, T., ob. cit., pp. 634-635.
} 


\section{6. ¿De qué manera conciliar eficiencia y debido proceso respecto de la solución del problema temporal del recurso de apelación?}

A partir de lo tratado en este trabajo, se hace necesario ratificar -a propósito del problema temporal de la apelación- la hipótesis planteada en un comienzo, en cuanto a que es posible conciliar las exigencias de debido proceso con aquellas pautas u orientaciones que provienen de la eficiencia.

Tal coincidencia viene dada en la apelación del proceso civil por mecanismos de inadmisibilidad vía discrecionalidad ex post, toda vez que tales instrumentos permiten limitar el número de apelaciones que son conocidas por el tribunal superior, filtrando aquellas apelaciones que están afectas a manifiesta falta de fundamento.

A modo de síntesis preliminar, hemos dicho que tal mecanismo previene los riesgos temporales del proceso de apelación, sin que con ello se vulnere el debido proceso, toda vez que la restricción del recurso de apelación no significa vulneración a tal garantía. En esa línea, abona tal punto el que sea menos exigente la conceptualización que existe del derecho al recurso en el proceso civil, de aquella que existe en el proceso penal.

De esta forma, no constituyendo una vulneración al debido proceso la restricción del recurso de apelación, los mecanismos de restricción ex post-inadmisibilidad en ejercicio de discrecionalidad por parte del tribunal superior- resultan mejores alternativas de regulación procesal que mecanismos ex ante que tiendan a la rapidez procedimental -aquellos asociados a la primacía del efecto devolutivo-, toda vez que la aversión al riesgo de la mayoría de los litigantes impide que en la práctica se ejecuten las resoluciones que causan ejecutoria.

A continuación señalamos que el establecimiento de un sistema de inadmisibilidad vía discrecionalidad ex post debía satisfacer un umbral mínimo, en cuanto a que no podía pasar a constituir, en la práctica, un sistema de única instancia por los riesgos de aumento de costos que ello supone. Asimismo, también señalamos que tal sistema de inadmisibilidad debía estar pensado en la lógica de resguardar el rol del tribunal superior -umbral mínimo-, cual es, la obtención de una decisión socialmente óptima, lo que se alcanza vía externalidades públicas positivas (precedente judicial).

Por tanto, en lo que resta, se dotará de contenido a tal causal de inadmisibilidad en atención a las consideraciones precedentemente reseñadas. Ello lo haremos en la sección siguiente y final.

6.1. La inadmisibilidad por falta de fundamento en casos en que resulta evidente que el recurso no constituye un caso especial, de acuerdo con las externalidades públicas positivas que ha producido la administración de justicia

De acuerdo con lo reseñado a lo largo de este trabajo, la propuesta de inadmisibilidad vía discrecionalidad ex post, que permite satisfacer exigencias de debido proceso y eficiencia para solucionar el problema temporal del sistema de apelación, es la siguiente: 
“El tribunal que conozca de un recurso de apelación podrá por la unanimidad de una sala legalmente constituida, y en cuenta, declarar inadmisible el recurso. Ello ocurrirá cuando los recursos que pretendan un cambio de las decisiones adoptadas por los tribunales superiores sobre el conflicto en cuestión, carezcan de fundamento suficiente para justificar tal cambio" ${ }^{\circ 0}$.

De esta forma, la inadmisibilidad solamente está pensada como un filtro de aquellos recursos que pretenden alterar sin fundamento un estado jurisprudencial pacífico (precedente judicial $)^{51}$, en el sentido que dicho estado contiene un criterio jurisprudencial uniforme respecto de alguna materia revisada vía apelación (por ejemplo, normas acerca de prescripción adquisitiva o extintiva, nulidad de contratos, notificación tácita, entre otras). En esos casos, sostener un sistema de apelación traerá escasos beneficios -por cuanto en el caso en cuestión, no existe fundamento para generar el cambio jurisprudencial-,

${ }^{50}$ Una fórmula similar se introdujo al sistema procesal civil inglés de las Civil Procedure Rules en (adelante CPR) de 1999 mediante la fórmula del real prospect of success. La apelación está regulada en las CPR 52 y en sus practice directions (CPR Part 52 disponible en https://www.justice.gov.uk/courts/procedure-rules/ civil/rules/part52 y Practices Directions 52 A, 52 B, 52 C, 52 D, 52 E disponibles en https://www.justice. gov.uk/courts/procedure-rules/civil/rules/part52/pd_part52) La apelación fue diseñada siguiendo el overriding objective (Zuckerman, Adrian, On Civil Procedure Principles of Practice, Third Edition, Sweet \& Maxwell, 2013, p. 1112). El overriding objective consiste en permitir a los tribunales tratar los casos de manera justa y a un costo proporcionado al asunto y a la situación financiera de las partes, asegurando un tratamiento rápido y un uso apropiado de los recursos de la Corte (Cfr. artículo 1.1, de la parte primera de las Civil Procedure Rules disponibles en http://www.justice.gov.uk/courts/procedure-rules/civil).

En efecto, lo que se busca es restringir el recurso solo a aquellos casos que lo justifiquen, y su objetivo es asegurar que las apelaciones sean conducidas de un modo eficiente y efectivo. La regulación de la apelación se conforma al principio de proporcionalidad, según este, si una parte ha tenido una oportunidad adecuada para presenter su caso y una decisión judicial ha sido tomada, cualquier otro paso por vía de apelación debe ser reservada para aquellos casos que realmente lo requieran. Se trata de un enfoque minimalista, manteniendo la apelación al mínimo compatible con la necesidad de evitar la injusticia. Esto limita la posibilidad de apelar a solo aquellos casos donde el apelante tenga una real perspectiva (real prospect) de éxito o cuando existan otras razones ponderosas (SoRABJI, John, English Civil Justice after Woolf and Jackson Reform, A Critical Analysis, Cambridge University Press, 2014, pp. 182 a 184).

La apelación, con pocas excepciones, está sujeta a permiso de la Corte. El permiso se otorga solo cuando la apelación tenga posibilidad de éxito o cuando exista un interés público. El objetivo es evitar el desperdicio de valiosos recursos con apelaciones sin destino y enfocando la atención de la apelación en asuntos que sean de real importancia para las partes o el público en general. El principio general es que si el tribunal inferior ha considerado los méritos de la apelación y ha decidido que no tiene real perspectiva de éxito, existe poca justificación para entregarle mayor atención en apelación, y el caso debe concluir (ZUCKERMAN, ob. cit., p. 1113).

Estas prescripciones no se fundan solo en la necesidad de economizar recursos, sino también fundado en la creencia que los tribunales inferiores deben mantener la responsabilidad por la conducción del caso y sus resultados. La apelación debe tener deferencia con la decisión, salvo aquellas manifiestamente erradas, en el sentido que es contraria a un principio establecido o que ningún juez razonable podría haber alcanzado la conclusión en cuestión (ZuCKerman, ob. cit., p. 1114).

${ }^{51}$ Esto conduce a un mejor control de los tribunales superiores respecto de los precedentes existentes, lo que favorece una supervisión a costo razonable. Respecto de la experiencia en Estados Unidos en relación con el compromiso de los tribunales inferiores con el precedente cuando existe una supervisión más intensa de la CS, puede verse Susan, H, Lindquist, S, Songer, "Appellate Court Supervision in the Federal Judiciary: A Hierarchical Perspective”, en Law and Society Review, 2003 (Vol. 37, N 1), pp. 143-168. 
frente a los costos de poner en marcha el sistema de apelación, lo que genera la necesidad de optimizar los recursos de los tribunales superiores ${ }^{52}$, frente a una litigación recursiva puramente dilatoria.

\section{Conclusiones}

A partir de lo expuesto en este trabajo, podemos llegar a las siguientes conclusiones:

(i) Acerca del derecho al recurso en el proceso civil chileno

1. Para dilucidar la procedencia del derecho al recurso, es necesario distinguir entre el proceso penal y el proceso civil. En ese orden de cosas, en el primero no cabe duda que es procedente el derecho al recurso como garantía fundamental.

2. En lo que respecta al proceso civil, el derecho al recurso no se encuentra consagrado, en la medida que ello no tiene correlato normativo en regulación nacional ni en los tratados internacionales sobre derechos humanos ratificados y actualmente vigentes en Chile. Es más, la jurisprudencia constitucional chilena, la interamericana y la europea reconocen que al proceso civil no le es aplicable tal garantía.

3. Atendido lo anterior, el legislador tiene un ámbito de discrecionalidad para crear, eliminar o modificar recursos en el proceso civil, sin perjuicio que debe respetar ciertas garantías o fortalecer otras instituciones procesales para crear y resguardar un proceso racional y justo.

4. Por consiguiente, la creación de un control de admisibilidad ex post para el recurso de apelación en el proceso civil no repugna al debido proceso, por el contrario, logra compatibilizarlo con los criterios del AED.

(ii) Respecto del recurso de apelación y su control de admisibilidad ex post, como factores que compatibilizan criterios de eficiencia con el debido proceso

1. Como se tuvo oportunidad de desarrollar al momento de revisar el proceso de apelación, el asunto central, considerando el factor tiempo como un escollo a resolver, es el conciliar la tramitación de apelaciones con la eficiencia que puede ser obtenida a partir de esa tramitación.

2. La construcción de la solución se basa en el análisis inicial de los elementos que permiten restringir el recurso de apelación, ya sean estos de aplicación ex ante o ex post, concluyendo que estos últimos son los idóneos, basados en un control de admisibilidad por parte de los tribunales superiores. Sin embargo, esa opción

52 Esto no implica un sistema de discrecionalidad absoluto, donde el tribunal de apelación tenga plena libertad para decidir qué apelaciones deben proceder. Un sistema totalmente discrecional implica un mal gasto de recursos por el sistema porque no considera el conocimiento de las partes que son víctimas de error, Shavell, S., ob. cit., 1995, pp. 385-393. Por ello, la propuesta fija ciertos criterios normativos. 
implica la restricción de las apelaciones, cuestión que repercutiría en las consideraciones de debido proceso.

3. Luego de un análisis del sistema recursivo chileno y las disposiciones previstas en instrumentos internacionales de derechos humanos, es posible admitir, sin lugar a dudas, que el control de admisibilidad ex post de las apelaciones no es contraria al debido proceso. Lo anterior, por cuanto el sistema de recursos chileno ya contempla una causal como la señalada a partir de la casación en el fondo y, por otra parte, el derecho al recurso consagrado en tratados internacionales tiene una raigambre netamente penal y, por lo mismo, no recibe aplicación en el proceso civil.

4. Una vez satisfechas las exigencias del debido proceso, procede colocar límites a la admisibilidad ex post propuesta. En ese sentido, el umbral mínimo viene dado por impedir que el control ex post torne al sistema en uno de única instancia, mientras que el umbral superior se constituye en la obligación del tribunal superior de admitir únicamente apelaciones que propendan a la obtención de una decisión socialmente óptima creando, por tanto, externalidades públicas positivas (precedente judicial).

5. Además, el control de admisibilidad funciona como una amenaza frente al juez inferior, de modo tal que adecue sus sentencias con el óptimo social generado por los fallos del tribunal superior. De esa forma, las decisiones superiores al ser conocidas por los jueces de primera instancia permiten el correcto enfoque de estos incentivándolos a no desviarse de la decisión socialmente eficiente.

6. En conclusión, la propuesta de inadmisibilidad vía discrecionalidad ex post es la siguiente:

"El tribunal que conozca de un recurso de apelación podrá por la unanimidad de una sala legalmente constituida, y en cuenta, declarar inadmisible el recurso. Ello ocurrirá cuando los recursos que pretendan un cambio de las decisiones adoptadas por los tribunales superiores respecto del conflicto en cuestión, carezcan de fundamento suficiente para justificar tal cambio".

7. De esta forma, la inadmisibilidad solamente está pensada como un filtro de aquellos recursos que pretenden alterar sin fundamento un estado jurisprudencial pacífico (precedente judicial), ya que ello justamente incide en el aumento de costos administrativos y del error, generando una externalidad pública positiva.

\section{BIBLIOGRAFÍA}

\section{a. Bibliografía citada}

Bordalí Salamanca, A., Cortez Matcovich, G. y Palomo Vélez, D., Proceso civil. El juicio ordinario de mayor cuantía, procedimiento sumario y tutela cautelar, Thomson Reuters, Santiago, 2014.

Carrasco, Nicolás, "La eficiencia procesal y el debido proceso", en Revista de Derecho Privado, 2017 ( N ${ }^{\circ} 32$ ).

CoAse, Ronald, "El problema del Costo Social”, en Revista de Estudios Públicos, 1992 (No 45). 
Comité de Derechos Humanos de las Naciones Unidas. Observación General No 32, de fecha 23 de agosto de 2007. Disponible en: http://www1.umn.edu/humanrts/hrcommittee/Sgencom32.pdf

Consejo de Europa. Guide to Article 6, Right to a Fair Trial, pp. 66. Disponible en: http:// www.echr.coe.int/Documents/Guide_Art_6_ENG.pdf

Cooter, R. y Ulen, T., Derecho y Economía, Fondo de Cultura Económica, Ciudad de México, DF, 1998.

Drahozal, C., "Judicial Incentives and the Appelas Process", en Southern Methodist University Law Review, 1998 (Vol. 51, Nº 3).

Duce, M., Fuentes, C., NúÑEz, R. y Riego, C., El derecho a un recurso y el proceso civil. Artículo publicado electrónicamente en El Mercurio Legal, 18 de diciembre de 2015. Disponible en: http://www.elmercurio.com/Legal/Noticias/Redes/Detallenoticia.aspx?id=904422

Kaplow, L. y Shavell, S., Fairness versus Welfare, Harvard University Press, Cambridge, 2002.

LupPI, B. y PARISI, F., "Judicial Creativity and Judicial Errors: and organizational perspective", en Journal of Institutional Economics, 2010 (Vol. 6, N 1).

Maturana, C. y Mosquera, M., Los Recursos Procesales, Editorial Jurídica de Chile, Santiago, 2010.

Moreso, J.J., La teoría del Derecho de Bentham, PPU, Barcelona, 1992.

Nogueira Alcalá, H., El debido proceso en la Constitución y el sistema interamericano, Librotecnia, Santiago, 2007.

NúÑEZ OJEDA, R., "El sistema de recursos procesales en el ámbito civil en un estado democrático deliberativo", en Revista Ius et Praxis, 2008 ( $\left.\mathrm{N}^{\circ} 14\right)$.

Núñez Ojeda, R. y Pérez-Ragone, Á., Manual de Derecho Procesal Civil, Los medios de impugnación, Thomson Reuters, Santiago, 2015.

Paolantonio, M.E., "El análisis económico del derecho y la estructura societaria", en Kluger, V. (coord.), Análisis Económico del Derecho, Heliasta, Buenos Aires, 2006.

Posner, R., El análisis económico del Derecho, Fondo de Cultura Económica, Ciudad de México DF, 1992.

Postema, G., Bentham and the Common Law Tradition. Clarendon Press, Oxford, 1986.

RaCHLInski, J., "Gains, Losses, and the Psychology of Litigation", en California Law Review, vol. 70, 1996.

Schafer, H.B. y Otт, C., Manual de Análisis Económico del Derecho Civil, Tecnos, Madrid, 1991.

Schwartz, E., "A Comment on: The Appeals as a Means of Error Correction. By Steven Shavell", en Legal Theory, 1995 (Vol. 1, No 3).

Shavell, S., Foundations of economic analysis of law, Belknap Press of Harvard University Press, Cambridge, 2004.

Shavell, S., "On the Design of the Appeals Process: The Optimal Use of Discretionary Review versus Direct Appeal”, en Journal of Legal Studies, 2010 (Vol. 39, N 1).

Shavell, S., "The Appeals Process and Adjudicator Incentives", en Journal of Legal Studies, 2006 (Vol. 35).

Shavell, S., "The Appeals Process as a means of error correction", en Journal of Legal Studies, 1995 (Vol. 24, N²).

SorABJI, John, English Civil Justice after Woolf and Jackson Reform, A Critical Analysis, Cambridge University Press, 2014.

Susan, H., Lindquist, S., Songer, "Appellate Court Supervision in the Federal Judiciary: A Hierarchical Perspective”, en Law and Society Review, 2003 (Vol. 37, N 1).

Valenzuela Villalobos, W., Derecho al recurso. Del sistema interamericano a la situación de Chile, EJS, Santiago, 2013.

YÁÑEZ Velasco, R., Derecho al recurso en el proceso penal, Tirant lo Blanch, Valencia, 2001.

Zuckerman, Adrian, On Civil Procedure Principles of Practice, Third Edition, Sweet \& Maxwell, 2013. 
b. Normas citadas

Constitución Política de la República de Chile.

PaCto Internacional de los Derechos Civiles y Políticos.

Convención Americana de Derechos Humanos.

Código Orgánico de Tribunales.

Código de Procedimiento Civil.

Proyecto de Código Procesal Civil. 
